
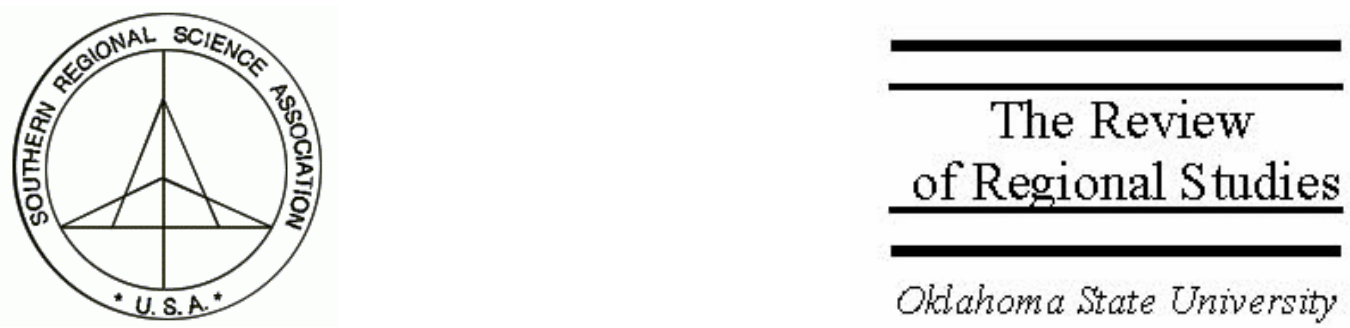

\title{
Policy Research in the Review of Regional Studies
}

\author{
Presidential Address \\ Southern Regional Science Association \\ March 2004 \\ Stephen M. Smith \\ Professor of Agricultural and Regional Economics, Department of Agricultural \\ Economics and Rural Sociology, The Pennsylvania State University \\ e-mail:smsmith@psu.edu
}

\begin{abstract}
Researchers in regional science generally describe their work as policy oriented. This paper examines articles in the Review for 1990-2002 to determine the extent to which they address policy, at three levels. A context for examining policy orientation is developed, and articles are judged within this context. Less than half of the articles focused on or mentioned policy. Of those that did, questions are raised about the usefulness of the policy recommendations or conclusions.
\end{abstract}

Keywords: Regional policy; Policy research; Policy recommendation

JEL classification: R58; O18; O21 


\section{INTRODUCTION}

Most of us likely view our journal as applied and the research that is published in it as policy oriented. We would all probably say that our own research is applied and is relevant to or directly applicable to policy. My own view, probably formed from almost 35 years in the Land Grant system, is that research has its greatest value when it can be applied to solve the problems of people and society - that is, when it is policy oriented. The policy content of research is not a recent concern. Over 50 years ago, Leonard Salter (1967) lamented that “. . . many researchers do not ask themselves what real problems of people their studies would help solve and what action could be taken as a result.”

The question that interests me is the extent to which the articles published in our journal are policy oriented. Most of us would say that, certainly, our research has policy implications. There is some dispute, however, within the regional science profession as to how much of our research actually is policy oriented.

In his Presidential Address at the $29^{\text {th }}$ Annual Meeting of the Southern Regional Science Association in 1990, David Rasmussen (1990, p.3) observed that:

Regional Science has important analytic tools with which to analyze problems of economic development. Yet the problems and policies that constrain development are not usually discussed by our discipline. . . . The issues of regional development policy . . . are not a regular part of our research agenda nor our discourse at meetings.

Isserman (1994, p.50) concurs, saying that “. . . scholars have played a meager role in the design and evolution of economic development policy," with the result being that practitioners have had to learn by doing.

More recently, Harrison Campbell, Jr., in the $30^{\text {th }}$ Anniversary Issue of The Review, came to a different conclusion. He noted four themes that emerged from a discussion in the International Regional Science Review. One was a general need for regional scientists to relate the relevance of their research to "real world" issues, and another was a need to explicitly tie our work to public policy issues and initiatives (Campbell 2000). His assessment was that we were not far from reaching the goals of relevance and public policy application. Campbell concluded that much of our research is premised on its application to public policy, and that is one of the discipline's greatest strengths.

Policy tries to influence decisions, actions, or behavior. Thus one context, or criterion, against which to measure a policy recommendation is that policy is a mechanism to bring about something - some change. To make policy effective, therefore, we need to know the mechanisms by which behavior changes. Thus, do the policy recommendations or conclusions in an article address the mechanisms of policy formation? That is, do they address how things get done? To be useful, policy recommendations must focus on things that can be influenced. 
One such mechanism is our institutions. Glenn Nelson (1984) maintained that institutions are the focus of policy, as they are the mechanisms through which "things get done." What does research contribute to this mechanism? Do findings or recommendations fit into, or are they workable, within the feasible mechanisms that are policy within the institutional structures that carry out the policy?

Another context, or criterion, is: what are the key factors or variables on which we focus to influence decisions or behavior? Are the variables used in the analysis "policy amenable," can they be affected by policy, do they fit into the policy mechanism? That is, what can we control through the policy actions to influence what we want to change? Perhaps another way to state this is to ask, "Is the recommendation practical or practicable?”

Related to the issue of practical or practicable is the "unit of assessment" that may be the focus of the policy recommendation. Is this the correct "unit," the unit/level at which the policy recommendation can reasonably be expected to be carried out?

A fourth potential context is provided by Michael Storper (1997) in his book The Regional World. Storper says that policy must have strategic content (pp. 267-268), that policy research must permit strategic assessments (p. 275) and place the economy or entity under consideration on a "trajectory of learning" [toward a goal] (p. 268).

Based on the foregoing, the following is a working set of criteria to assess the policy content of articles in the Review:

- Does the policy recommendation address an institution through which the policy must be carried out? That is, does it address the "mechanisms of policy formation,” does it address how things get done?

- Are the key factors identified amenable to policy action? Can they be controlled, particularly by the policy-making unit under consideration?

- Is the policy unit, or governmental level, at which the policy supposedly will be carried out identified?

- Will the policy recommendation fit within a larger strategy of strategic planning toward a goal, or is it only stop-gap or short term?

The objective I set for myself was to examine articles in The Review of Regional Studies for policy content, focusing on 1990 through 2002. A problem I realized as I began was how was I to proceed? Would I simply list the number or percentage of articles, or would I place them into a particular context? Certainly a more satisfying approach would be to assess each article within a context and determine whether the policy recommendation in the article fit the criteria. 
Reading each article turned out to be more than I and a graduate student could do. Thus, each article was initially looked at to determine whether policy was simply mentioned either in the introduction and/or in the conclusion, in the context of applying the article's results.

The result of this exercise was that out of the 172 articles in the volumes of The Review that were examined, 69 (40\%) either contained an explicit policy statement or focused on policy. There seemed to be a trend toward an increasing focus on policy beginning in 1997, reaching 50\% of the articles in 2000 and 2001, but dropping off slightly in 2002.

While not explicitly mentioning policy, a number of articles did examine impacts of policies or impacts of government regulations or decisions. Examples are resource and environmental policies, business location subsidies, infrastructure decisions, taxes, landuse decisions, welfare reform. Many of these articles actually had more policy content, or were more policy-relevant, than those that explicitly stated a policy focus. However, someone would have to dig through them to pull this out. So, we could probably say that Campbell (2000) may have been right when he said that the discipline does focus on public policy issues and that we are moving in the right direction.

The fact that policy might have been mentioned in the introduction or conclusion of an article does not mean that policy content or application was actually addressed. Only a few of the articles started from a policy context. Most started with a research topic and then drew a policy implication. Not infrequently, for example, there will be only one sentence in either the introduction or conclusion simply stating that "the results have policy implications" or "should be considered in policy formation."

The following are some of the one-sentence "policy-relevant" statements I found (more or less direct quotes).

- These results may be of interest to policy makers intent on controlling the entrance of certain industries in local areas.

- Policies should be developed to promote human capital accumulation.

- This information provides valuable insights that can be used by policy makers.

- The results are suitable for developing regional policy.

- This information is important for policymaking by public agencies and officials.

Useful to whom, for what, how?

To try to make my analysis a little more substantive, I took three of the questions from the above set of working criteria. I left out the fourth, as it would take considerable 
time and analysis. So the three criteria I applied to each article that mentioned policy were these.

1. Did it address the "mechanisms" of policy - how the policy should be carried out?

2. Were the policy factors or variables identified amenable to policy action, certainly by the level of government that would be involved?

3. Was the unit of government identified that would need to implement the policy?

The empirical results, clearly based on my own arbitrary decision, were as follows.

$$
\begin{array}{lll}
\text { Question \#1: } & \text { Yes }-23 \% \text {, with another 9\% more or less; } & \text { No }-68 \% \\
\text { Question \#2: } & \text { Yes }-49 \% \text {, with 13\% more or less; } & \text { No }-38 \% \\
\text { Question \#3: } & \text { Yes - 49\%, with 5\% more or less; } & \text { No }-46 \%
\end{array}
$$

These are the results from the $40 \%$ of the articles that specifically mentioned policy. Thus, we are focusing on half of $40 \%$.

For question \# 1, at most only one quarter to less than one third approached the issue of "how the policy should get done," or an institution through which it should be carried out. If, as Glenn Nelson maintains, policies are really directed at institutions or institutional forms then policy recommendations from our research should include some realization that how it could get done is necessary.

For question \# 2, encouragingly, in up to $60 \%$ of the articles the factors or variables identified as key to policy were ones that policymaking bodies could influence or manipulate. Perhaps discouragingly, in 38\% of the articles it was my opinion that the variables the authors said were key to policy formation could not be controlled or influenced by policymaking bodies and certainly not by local public bodies. Examples are levels and distribution of income, age or ethnic distribution, national unemployment rates, or climate and natural resources.

This is one area of our research that I will criticize. We should at least recognize that certain of our regressions results, no matter how statistically significant, may have no practical policy content or relevance. It advances our knowledge and its usefulness very little to report research in a supposed policy-relevant framework, but where our most important results cannot be applied at any level of public policy.

For the third question, only about half of the articles specifically identified the unit of government at which the policy needed to be carried out, and this includes those where it was clear by implication that only the federal or state government or a school district was the appropriate unit. 
A particularly interesting realization I had was that many articles identified some amorphous "regional” body or "regional policymakers" as the unit of focus to carry out a recommended policy. This may be a natural inclination, given our self-identification as regional scientists. However, there are few regional bodies that have the responsibility or power to generate or implement policy. Should we not go the next step and specifically single out the governmental unit we think should take action?

At this point I think I should invoke the "people who live in glass houses shouldn't throw stones" caveat. Judging my own article published in our journal two years ago on these three criteria, I received a "no" on all three. And in the comments accompanying my most recent article rejection of a couple of months ago was the question by a reviewer of who was supposed to carry out all the policy recommendations I had made. Although some in this room are as bad as I am, I won't single you out. Others consistently ranked quite high - Mark Partridge, Dan Rickman, and Ernie Goss, to mention three.

\section{WHAT HAVE I LEARNED, OR WHAT DO I CONCLUDE?}

One conclusion I reached is that I am definitely in favor of our journal being online. It appears that there is an expiration date on the glue holding the pages together. After thumbing through them, all my issues before 1997 are now loose leaf. Another conclusion that my cynicism as I age leads me to say, only partly in jest, was that I reacted to some of the conclusions in the articles by saying "no kidding, you don't need a Ph.D. nor a whole research project to say that." On a more professional note, the fact is that in much of our research:

- the "mechanisms" of policy formation are seldom addressed;

- we frequently do not explicitly recognize that key variables are not controllable by the governmental unit charged with the policy; and

- we often do not really think about which governmental unit has to formulate and implement a policy recommendation.

These make our policy recommendations much less useful. Does this mean that we don't really know the policy context, even though we maintain that our work is policy oriented?

Returning to Isserman's comment that we have played a meager role in the design and evolution of policy, if our interest is in the policy implications of our research, if we want our results to have influence in policy formation, we will have to take our research more specifically into the policy realm.

If we do not do it ourselves, to whom will we leave it?

Who will translate our research so that the correct policy makers can use it? 


\section{REFERENCES}

Campbell, H.S., Jr., 2000. "Education, Training, and Regional Development: A Policy Relevant Agenda for Regional Science,” The Review of Regional Studies 30(1), 8591.

Isserman, A., 1994. "State Economic Development Policy and Practice in the United States: A Survey Article,” International Regional Science Review 16(1 \& 2), 49-99.

Nelson, G.L., 1984. "Elements of a Paradigm for Rural Development," American Journal of Agricultural Economics (December), 694-700.

Rasmussen, D.W., 1990. "Drugs, Tsars and Economic Development," The Review of Regional Studies 20(3), 1-3.

Salter, L.A., Jr., 1967. A Critical Review of Research in Land Economics. University of Wisconsin Press: Madison, WI.

Storper, M., 1997. The Regional World. The Guilford Press: New York.

Westeren, K.I., 2003. "Spread of Knowledge: Effects from Regional Competitiveness and Rural Growth,” paper presented at the 2003 North American Regional Science Association meetings, Philadelphia, PA. Nord-Trondelag University College, Box 145, N-7713 Steinkjer. 